\title{
Radionuclide behavior in high-temperature gases from Satsuma Iwojima volcano, Japan
}

\author{
M. F. Le Cloarec ${ }^{1}$ and M. Pennisi ${ }^{2}$ \\ ${ }^{1}$ LSCE, Laboratoire mixte CNRS-CEA, 91190 Gif sur Yvette, France \\ ${ }^{2}$ Istituto di Geocronologia e Geochimica Isotopica, CNR, 56127 Pisa, Italy
}

(Received November 13, 2000; Revised January 25, 2002; Accepted January 27, 2002)

\begin{abstract}
Radionuclide and sulfur measurements were performed on samples from plume and hot fumarolic gas discharged from Satsuma Iwojima volcano, Japan. Such measurements in volcanic plumes contribute to a better understanding of degassing mechanisms (emanation coefficient of metals, degassing magma volume, residence time of the magma). At Satsuma Iwojima, inferred emanation coefficients of ${ }^{210} \mathrm{~Pb}$ and ${ }^{210} \mathrm{Po}$ were estimated to be 0.07 and $2.5 \%$, respectively, the lowest values obtained to date in volcanic gases. These values may be "apparent" emanation coefficients, due to the high viscosity of the degassing magma, which prevents efficient degassing of such low concentration components. The volume of the degassing reservoir (rhyolite layer) is estimated to be $0.24 \mathrm{~km}^{3}$, assuming no radionuclide recharge from the underlying basaltic reservoir to the degassing rhyolite.
\end{abstract}

\section{Introduction}

Radionuclide measurements in volcanic plumes provide useful indications of degassing processes such as volume of degassing magma or the escape time of gases (Lambert et al., 1986; Gauthier et al., 2000). The last decay products of the ${ }^{238} \mathrm{U}$ series, ${ }^{210} \mathrm{~Pb}\left(T_{1 / 2}=22\right.$ years $),{ }^{210} \mathrm{Po}\left(T_{1 / 2}=4.6\right.$ months) and ${ }^{210} \mathrm{Bi}\left(T_{1 / 2}=5\right.$ days $)$, which are assumed to be in radioactive equilibrium in the deep magma, are chemical species which are volatile at magmatic temperatures. They are enriched in gases, according to their specific volatility, leading to radioactive disequilibria in the gaseous phase. These radionuclides are thus potential tracers of events having different time scales, from as much as 100 years to a few years, and even a few weeks, according to their different half-lives.

Studies over long periods at Mount Etna and Stromboli allowed degassing models to be proposed (Lambert et al., 1986; Gauthier et al., 2000), based on the idea that the degassing takes place from a shallow reservoir located in the upper part of the magma chamber. This leads to the estimation of parameters such as emanation coefficients of Po, Bi and $\mathrm{Pb}$ between the gaseous phase and the magma, the time elapsed between the separation of gas from the magma and its emission to the atmosphere, or renewal of non-degassed magma in the degassing reservoir by convective movement. Radionuclide measurements performed during short periods at White Island volcano, New Zealand, and Mount St Helens, USA, allowed the volume of degassing magma at the time of sampling to be estimated, from the knowledge of ${ }^{210}$ Po fluxes and ${ }^{210}$ Po magmatic content before degassing. At White Island continuous renewal of the degassing reser-

Copy right (C) The Society of Geomagnetism and Earth, Planetary and Space Sciences (SGEPSS); The Seismological Society of Japan; The Volcanological Society of Japan; The Geodetic Society of Japan; The Japanese Society for Planetary Sciences. voir was assumed (Le Cloarec et al., 1992), whereas the reservoir at Mount St Helens was assumed to be nearly motionless (Le Cloarec et al., 1986).

We have investigated radionuclide behavior in hot fumarolic gases emitted from Satsuma Iwojima volcano, Japan. The current activity of this volcano is described in detail by Saito et al. (2001). High-temperature fumarolic gases (up to $880^{\circ} \mathrm{C}$ ) are emitted at Iwodake from a magma that is thought to be rhyolitic at $950-1000^{\circ} \mathrm{C}$ (Saito et al., 1997). The last eruption occurred 1300 years ago. The high temperature of the gases, as well as the permanent flux of $\mathrm{SO}_{2}$, averaging $550 \mathrm{~T} /$ day (Kazahaya et al., 2002), require that non-degassed magma convects in the shallow part of the reservoir where the degassing takes place. Kazahaya et al. (2002) propose that the degassing occurs from a two-layered reservoir: the degassed magma returns at depth, owing to its higher density, and is recharged in volatiles emitted by an underlying basaltic layer. The present rhyolite is thought to be fully degassed, and acts as the transporter of dissolved gases from the underlying basalt to the surface.

\section{Sampling and Analysis}

Sampling was performed in November 1997, either directly in the plume, at the rim of the crater (series 1 and 2), or at the end of silica tubes inserted into hot fumaroles to collect sublimates (series 3). Radionuclide sampling was performed at the same place and time together with $\mathrm{SO}_{2}, \mathrm{Cl}^{-}$ and $\mathrm{F}^{-}$sampling. The techniques of sampling and radioactivity measurements were described by Polian and Lambert (1979). Several cubic meters of the diluted plume are filtered through a cellulose filter, at a flow rate of about $8 \mathrm{~m}^{3}$ per hour. Subsequently, the gross $\alpha$ and $\beta$ radioactivities are measured during a period of several months and the ${ }^{210} \mathrm{~Pb}$, ${ }^{210} \mathrm{Bi}$ and ${ }^{210} \mathrm{Po}$ activities at the sampling time are calculated from the known rate of radioactivity decay. The sampling 
Table 1(a). Radionuclides and $\mathrm{SO}_{2}$ content in aerosols sampled at Satsuma Iwojima in November 1997.

\begin{tabular}{|c|c|c|c|c|c|c|c|c|c|}
\hline $\mathrm{n}^{\circ}$ & & $\begin{array}{l}{ }^{210} \mathrm{~Pb} \\
\mathrm{~Bq} / \mathrm{m}^{3}\end{array}$ & $\begin{array}{c}{ }^{210} \mathrm{Bi} \\
\mathrm{Bq} / \mathrm{m}^{3}\end{array}$ & $\begin{array}{l}{ }^{210} \mathrm{Po} \\
\mathrm{Bq} / \mathrm{m}^{3}\end{array}$ & $\begin{array}{c}\mathrm{SO}_{2} \\
\mathrm{mg} / \mathrm{m}^{3}\end{array}$ & $\begin{array}{c}{ }^{210} \mathrm{Po} / \mathrm{SO}_{2} \\
\mathrm{~Bq} / \mathrm{mg}\end{array}$ & $\begin{array}{c}{ }^{210} \mathrm{~Pb} / \mathrm{SO}_{2} \\
\mathrm{~Bq} / \mathrm{mg}\end{array}$ & ${ }^{210} \mathrm{Po} /{ }^{210} \mathrm{~Pb}$ & ${ }^{210} \mathrm{Bi} /{ }^{210} \mathrm{~Pb}$ \\
\hline \multicolumn{10}{|c|}{ plume } \\
\hline 1.1 & $02 / 11$ & 0.0031 & 0.065 & 0.040 & 9.51 & 0.0042 & 0.00033 & 13 & 21 \\
\hline 1.2 & $02 / 11$ & 0.0012 & 0.069 & 0.049 & 3.68 & 0.0134 & 0.00034 & 42 & 58 \\
\hline 2.1 & $03 / 11$ & 0.0037 & 0.047 & 0.170 & 21.63 & 0.0079 & 0.00017 & 44 & 13 \\
\hline 2.2 & $03 / 11$ & 0.0044 & 0.049 & 0.184 & 24.03 & 0.0076 & 0.00018 & 41 & 11 \\
\hline 2.3 & $03 / 11$ & 0.0058 & 0.073 & 0.209 & 24.41 & 0.0086 & 0.00024 & 37 & 13 \\
\hline 2.4 & $03 / 11$ & 0.0031 & 0.064 & 0.144 & 26.50 & 0.0054 & 0.00012 & 43 & 21 \\
\hline \multicolumn{10}{|c|}{ end of silica tube } \\
\hline 3.2 & $06 / 11$ & 0.0375 & 2.921 & 1.650 & 216.93 & 0.0076 & 0.00017 & 47 & 78 \\
\hline 3.3 & $06 / 11$ & 0.0250 & 1.829 & 0.896 & 268.71 & 0.0033 & 0.00009 & 38 & 73 \\
\hline 3.4 & $06 / 11$ & 0.0583 & 3.071 & 2.750 & 58.29 & 0.0472 & 0.00100 & 47 & 53 \\
\hline \multicolumn{6}{|c|}{ mean value } & $0.0073^{*}$ & $0.00021^{*}$ & 39 & \\
\hline \multicolumn{6}{|c|}{ one standard deviation } & 0.0031 & 0.00009 & 10 & \\
\hline
\end{tabular}

*discarding point 3.4 .

Table 1(b). Cl, F and S content in the plume sampled at Satsuma Iwojima, November 1997.

\begin{tabular}{lccccccc}
\hline & & $\begin{array}{c}\mathrm{S} \\
\mathrm{mg} / \mathrm{m}^{3}\end{array}$ & $\begin{array}{c}\mathrm{Cl} \\
\mathrm{mg} / \mathrm{m}^{3}\end{array}$ & $\begin{array}{c}\mathrm{F} \\
\mathrm{mg} / \mathrm{m}^{3}\end{array}$ & $\begin{array}{c}\mathrm{Cl} / \mathrm{F} \\
\mathrm{mg} / \mathrm{mg}\end{array}$ & $\begin{array}{c}\mathrm{Cl} / \mathrm{S} \\
\mathrm{mg} / \mathrm{mg}\end{array}$ & $\begin{array}{c}\mathrm{F} / \mathrm{S} \\
\mathrm{mg} / \mathrm{mg}\end{array}$ \\
\hline $\mathrm{plume}$ & 1997 & & & & & & \\
1.1 & $02 / 11$ & 4.76 & 9.0 & 0.60 & 15.0 & 1.9 & 0.13 \\
1.2 & $02 / 11$ & 1.84 & 1.4 & 0.21 & 6.6 & 0.7 & 0.11 \\
2.1 & $03 / 11$ & 10.82 & 7.0 & 0.44 & 16.0 & 0.6 & 0.04 \\
2.2 & $03 / 11$ & 12.02 & 8.3 & 0.43 & 19.3 & 0.7 & 0.04 \\
2.3 & $03 / 11$ & 12.21 & 5.5 & 0.40 & 13.8 & 0.5 & 0.03 \\
2.4 & $03 / 11$ & 13.25 & $\mathrm{nd}$ & $\mathrm{nd}$ & - & - & - \\
$\mathrm{end}$ of silica tube & & & & & & \\
3.2 & $06 / 11$ & 108.46 & 110.9 & 6.55 & 16.9 & 1.0 & 0.06 \\
3.3 & $06 / 11$ & 134.36 & 114.1 & 10.95 & 10.4 & 0.8 & 0.08 \\
3.4 & $06 / 11$ & 29.14 & 21.8 & 2.08 & 10.5 & 0.7 & 0.07 \\
\hline
\end{tabular}

device for $\mathrm{SO}_{2}, \mathrm{Cl}^{-}$and $\mathrm{F}^{-}$consists of a filter holder connected to a small pump. The flow rates are 4.5 and 4.2 $1 /$ min for $\mathrm{SO}_{2}$ and halogens, respectively. Sampling times vary from 3 to 20 minutes depending on the density of the plume. Each filter holder contains two Millipore filters in series impregnated following the techniques described by Faivre-Pierret (1983). After sampling, filters are washed and subsequently analyzed for $\mathrm{Cl}^{-}$by chromatography, for $\mathrm{F}^{-}$ by specific electrode, and for $\mathrm{SO}_{2}$ by colorimetry.

\section{Analytical Results}

All results are shown in Table 1. According to the sampling method, variations of the elemental content on filters are due to atmospheric dilution. Thus, if elemental addition or depletion do not occur during period between the gas emission at surface and the sampling time, elemental corre- lations should follow linear trends, thus allowing the typical elemental ratios to be defined in the fluid. The radionuclide and $\mathrm{S}, \mathrm{Cl}$ and $\mathrm{F}$ contents of the gases are far lower when the sampling is performed at the rim of the crater (series 1 and 2) compared with the samples collected near the output of the fumaroles (series 3), which experience less atmospheric dilution.

The $\left({ }^{210} \mathrm{Po} /{ }^{210} \mathrm{~Pb}\right)$ ratios do not show a large range of variation, except for sample 1.1, and have a mean value of $41.4 \pm 2.7$ in the diluted plume, and slightly higher mean value $(44 \pm 5)$ at the end of the silica tubes. The slopes of the lines ${ }^{210} \mathrm{Po}$ versus ${ }^{210} \mathrm{~Pb}$ are $39(r=0.83)$ and $45(r=0.98)$ at the two locations respectively (Fig. 1), consistent with the hypothesis of atmospheric dilution of a single magmatic source of radionuclides.

The $\left({ }^{210} \mathrm{Po} / \mathrm{SO}_{2}\right)$ and $\left({ }^{210} \mathrm{~Pb} / \mathrm{SO}_{2}\right)$ ratios have mean val- 


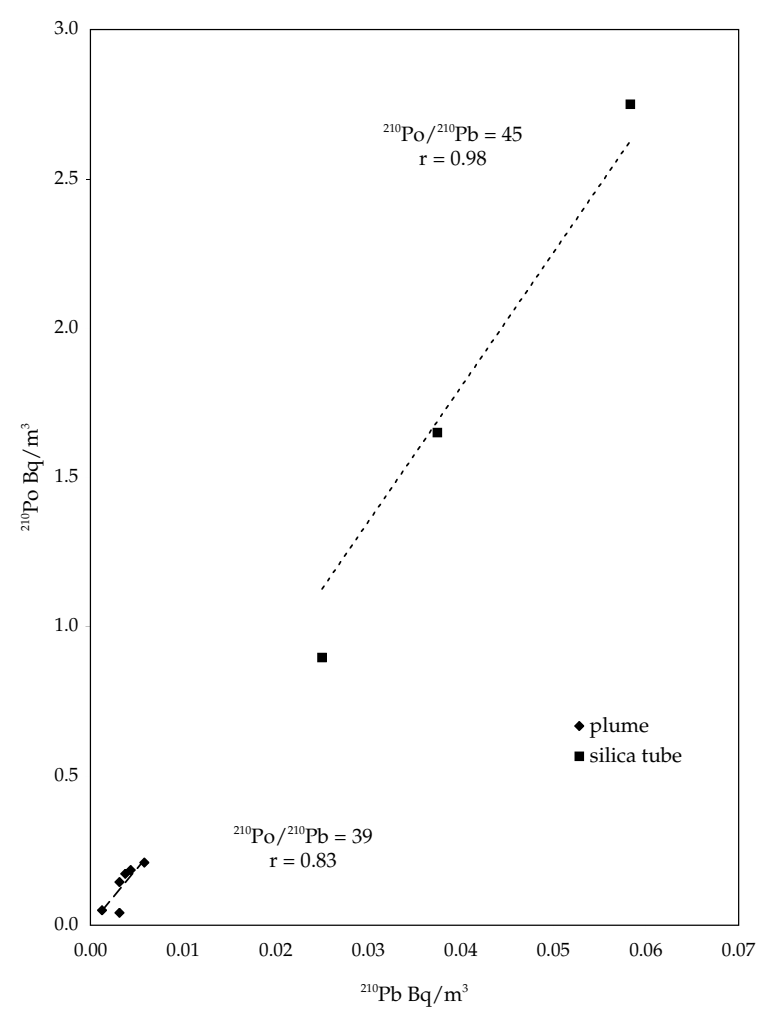

Fig. 1. Correlation between ${ }^{210} \mathrm{Po}$ and ${ }^{210} \mathrm{~Pb}$ in Satsuma Iwojima gases.

ues of $0.0073( \pm 0.0031) \mathrm{Bq} / \mathrm{mg}$ and $0.00021( \pm 0.00009)$ $\mathrm{Bq} / \mathrm{mg}$, respectively, discarding sample 3.4 , which is out of the variation range of the ratios. The slope of the lines ${ }^{210} \mathrm{Po}$ versus $\mathrm{SO}_{2}$ and ${ }^{210} \mathrm{~Pb}$ versus $\mathrm{SO}_{2}$ are $0.0072 \mathrm{~Bq} / \mathrm{mg}$ $(r=0.90)$ and $0.00018 \mathrm{~Bq} / \mathrm{mg}(r=0.62)$, respectively, suggesting a common magmatic origin for ${ }^{210} \mathrm{Po},{ }^{210} \mathrm{~Pb}$ and $\mathrm{SO}_{2}$ (Fig. 2).

The case of ${ }^{210} \mathrm{Bi}$ appears to be different. The $\left({ }^{210} \mathrm{Bi} /\right.$ $\left.{ }^{210} \mathrm{~Pb}\right)$ ratios are lower at the crater rim $(23 \pm 18)$ than in gases sampled at the end of silica tubes $(68 \pm 13)$. In the plume, the $\left({ }^{210} \mathrm{Bi} /{ }^{210} \mathrm{~Pb}\right)$ ratios can be compared to those observed in plumes from an open conduit volcano: about 20 at Stromboli in 1996 (Gauthier et al., 2000) and about 25 at Mount Etna during the period 1976-1995 (Le Cloarec and Pennisi, 2001). Higher $\left({ }^{210} \mathrm{Bi} /{ }^{210} \mathrm{~Pb}\right)$ ratios are currently observed in fumarolic gases, and are ascribed to the decay of ${ }^{210} \mathrm{~Pb}$ sublimates deposited along the pathway of the gases toward the surface (Le Cloarec and Gauthier, 2001). New ${ }^{210} \mathrm{Bi}$ atoms are created which enter the gaseous phase, due to the higher volatility of this element compared to that of ${ }^{210} \mathrm{~Pb}$, leading to the observed $\left({ }^{210} \mathrm{Bi} /{ }^{210} \mathrm{~Pb}\right)$ ratios being higher than those measured directly in the plume.

Elemental ratios $\mathrm{Cl} / \mathrm{S}$ and $\mathrm{F} / \mathrm{S}$ are the slopes of the lines $\mathrm{Cl}$ versus $\mathrm{S}$ and $\mathrm{F}$ versus $\mathrm{S}$, respectively. Correlations between $\mathrm{Cl}$ and $\mathrm{S}, \mathrm{Cl}$ and $\mathrm{F}$, and $\mathrm{F}$ and $\mathrm{S}$ are shown in Fig. 3. On Figs. 3(a) and 3(b), all correlations define linear trends, with $0.96<r<0.99$. This result confirms that a common magmatic source is feeding the fumarolic fluids emitted at Iwodake crater. The $\mathrm{Cl} / \mathrm{F}$ ratio is 12 , somewhat lower than the value of about 20 reported by Shinohara et al. (1993). The $\mathrm{Cl} / \mathrm{S}$ ratio is 0.9 (Fig. 3(b)), in agreement with $\mathrm{Cl} / \mathrm{S}=$

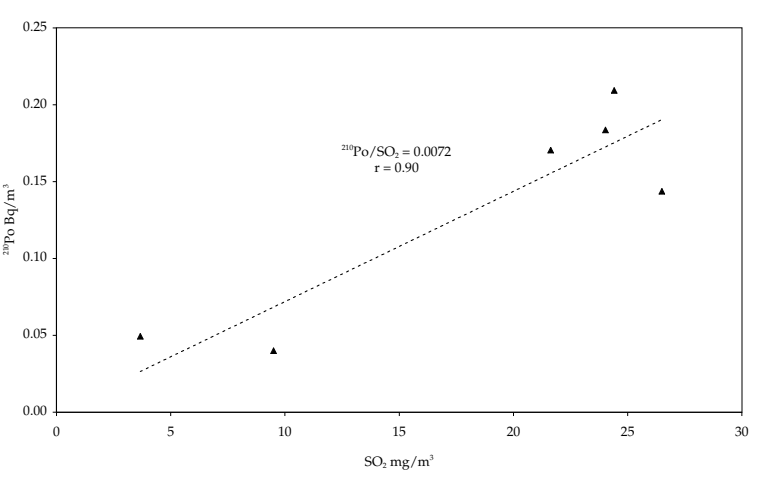

Fig. 2(a). Correlation between ${ }^{210} \mathrm{Po}$ and $\mathrm{SO}_{2}$ in series 1 and 2 in Satsuma Iwojima gases.

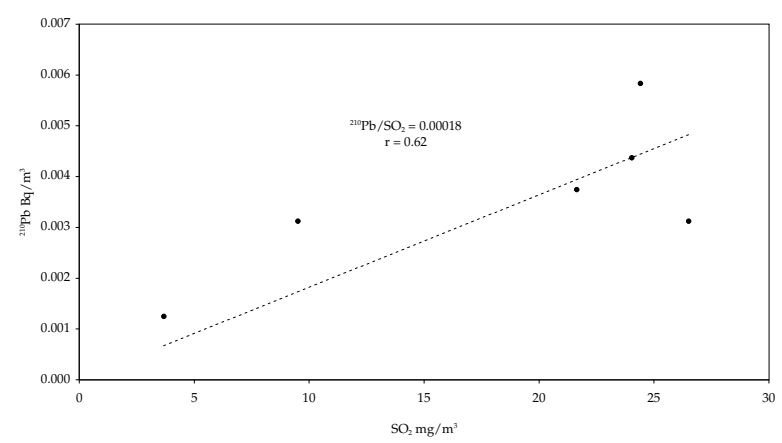

Fig. 2(b). Correlation between ${ }^{210} \mathrm{~Pb}$ and $\mathrm{SO}_{2}$ in series 1 and 2 in Satsuma Iwojima gases.

0.6 reported by Shinohara et al. (1993) and $\mathrm{Cl} / \mathrm{S}=0.7$ reported by Hedenquist et al. (1994). The F/S ratio is 0.07 , twice that reported by Shinohara et al. (1993).

\section{Emanation Coefficients $(\varepsilon)$}

The radionuclide ratios measured in volcanic gases are controlled by characteristic emanation coefficients $(\varepsilon)$ of radionuclides defined as a partition between gas and lava (Gill et al., 1985):

$$
\varepsilon=\left(C_{i}-C_{f}\right) / C_{i}
$$

where $C_{i}$ is the initial radionuclide concentration in magma before degassing and $C_{f}$ its final concentration in degassed magma. At a given volcano emanation coefficients can be inferred from the knowledge of one, $\varepsilon_{M}$, following the equation:

$$
\begin{aligned}
& (X / M)_{\text {gas }} /(X / M)_{\text {lava }} \\
& \quad=\left(\varepsilon_{X} / \varepsilon_{M}\right) /\left[\left(1-\varepsilon_{X}\right) /\left(1-\varepsilon_{M}\right)\right] .
\end{aligned}
$$

The difficulty is to determine $\varepsilon_{M}$ properly.

Radionuclide measurements at the same time as $\mathrm{SO}_{2}$ measurements in a plume provide a way to estimate the emanation coefficient of ${ }^{210} \mathrm{~Pb}, \varepsilon_{\mathrm{Pb}}$, owing to its very long half-life which prevents it from decaying appreciably after its emission from the magma. Any $X$ component in the gases is related to its initial concentration in the magma by

$$
\left(C_{X}\right)_{\mathrm{gas}}=\varepsilon_{X} *\left(C_{X}\right)_{\mathrm{magma}} * f
$$




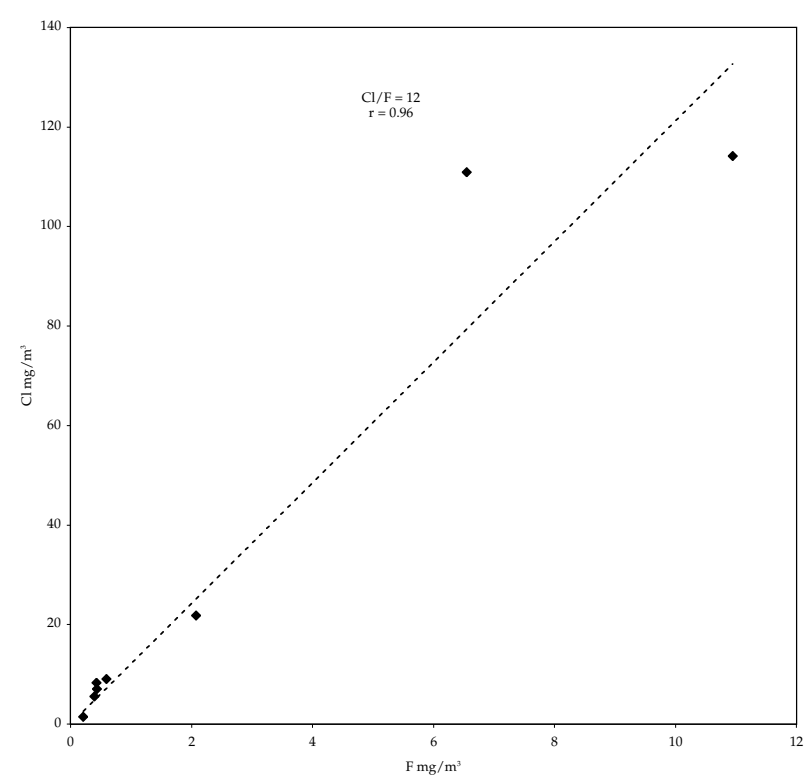

Fig. 3(a). Correlation between $\mathrm{Cl}$ and $\mathrm{F}$ in Satsuma Iwojima gases.

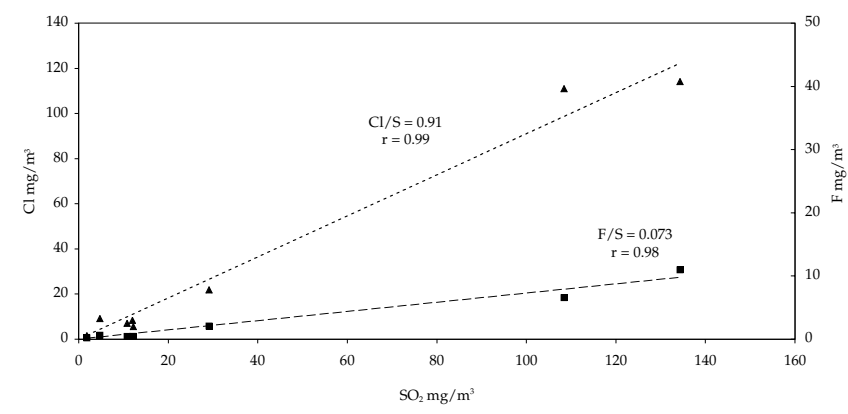

Fig. 3(b). Correlation between $\mathrm{Cl}$ and $\mathrm{S}$ (full triangles) and $\mathrm{F}$ and $\mathrm{S}$ (full squares) in Satsuma Iwojima gases (series 1, 2, 3).

where $f$ is a factor relating the degassing volume to its gas content. Thus ${ }^{210} \mathrm{~Pb} / \mathrm{SO}_{2}$ ratio in the main plume is

$$
\left({ }^{210} \mathrm{~Pb} / \mathrm{SO}_{2}\right)=\varepsilon_{\mathrm{Pb}} * A_{\mathrm{Pb}} / \varepsilon_{\mathrm{SO}_{2}} * C_{\mathrm{SO}_{2}}
$$

where $A_{\mathrm{Pb}}$ is the activity of ${ }^{210} \mathrm{~Pb}$ and $\mathrm{C}_{\mathrm{SO}_{2}}$ the $\mathrm{SO}_{2}$ concentration in the magma before degassing. The estimation of $\varepsilon_{\mathrm{Pb}}$ inferred from Eq. (3) leads to the estimation of any $\varepsilon_{M}$, using Eq. (1), provided that $M$ has been measured in gases and associated lavas.

\subsection{Emanation coefficient of $\mathbf{P b}$}

Saito et al. (2001), present a detailed analysis of melt inclusions in different lavas emitted by the volcano in the past. They emphasize that the volatile composition of Showa Iwojima rhyolitic melt agrees with that of the presently discharging high-temperature volcanic gases, suggesting a magma with similar composition as the source of the volcanic gases. Thus $\mathrm{C}_{\mathrm{SO}_{2}}$ will be taken equal to the mean value in Showa Iwojima melt inclusions, $0.220 \mathrm{mg} / \mathrm{g}$ (Saito et al., 2001); $\varepsilon_{\mathrm{SO}_{2}}$ will be taken equal to $0.82( \pm 0.09)$, as suggested by $\mathrm{S}$ concentration measurements in Showa Iwojima melt inclusions $(0.110 \pm 0.020 \mathrm{mg} / \mathrm{g})$ and matrix glass (maximum $0.020 \pm 0.010 \mathrm{mg} / \mathrm{g}$; Shinohara and Saito, pers.
Table 2. Abundance of trace $\mathrm{Pb}$ and $\mathrm{Bi}$ in Satsuma Iwojima lava and associated gases.

\begin{tabular}{cccc}
\hline Element & rhyolite & sample 2.1 & sample 2.2 \\
& $\mathrm{ppm}$ & $\mu \mathrm{g} / \mathrm{m}^{3}$ & $\mu \mathrm{g} / \mathrm{m}^{3}$ \\
\hline $\mathrm{Bi}$ & $0.74^{1}$ & $1.44^{1}$ & $1.56^{1}$ \\
$\mathrm{~Pb}$ & $17.7^{1}$ & $12.11^{2}$ & $16.00^{2}$ \\
$\mathrm{Bi} / \mathrm{Pb}$ & 0.042 & 0.12 & 0.10 \\
\hline
\end{tabular}

${ }^{1}$ measurements performed by ICP-MS (A. Gaudry, pers. comm., 2000).

${ }^{2}$ measurements performed by atomic absorption spectrometry, this work.

comm., 2001). We measured the ${ }^{210} \mathrm{~Pb}$ activity in the rhyolite, $0.058( \pm 0.002) \mathrm{Bq} / \mathrm{g}$, and we assume that this value is very close to the ${ }^{210} \mathrm{~Pb}$ activity in non degassed magma; indeed, our studies on other volcanoes indicate that $\varepsilon_{\mathrm{Pb}}$ is not higher than 1\% (Pennisi et al., 1988; Le Cloarec et al., 1992; Gauthier et al., 2000), which is less than the uncertainty of activities analysis. From ${ }^{210} \mathrm{~Pb} / \mathrm{SO}_{2}=0.00021( \pm 0.00009)$, the value of $\varepsilon_{\mathrm{Pb}}=0.07( \pm 0.04) \%$, about ten times lower than typical values.

\subsection{Emanation coefficient of ${ }^{210} \mathrm{Bi}$}

${ }^{210} \mathrm{Bi}$ has a very short half-life, about 5 days, which allows it to be continuously renewed from the parent ${ }^{210} \mathrm{~Pb}$ present in the degassing magma. Thus, the $\left({ }^{210} \mathrm{Bi} /{ }^{210} \mathrm{~Pb}\right)$ ratio cannot be used to infer the emanation coefficient of $\mathrm{Bi}$ from that of ${ }^{210} \mathrm{~Pb}$. Assuming that $\varepsilon_{210} \mathrm{~Pb}=\varepsilon_{\mathrm{Pb}}$ and that $\varepsilon^{210} \mathrm{Bi}=$ $\varepsilon_{\mathrm{Bi}}$, the emanation coefficient of ${ }^{210} \mathrm{Bi}$ is estimated from stable $\mathrm{Bi}$ and $\mathrm{Pb}$ measurements in aerosols collected from the plume in 1997, and in old rhyolitic lavas (Table 2), following Eq. (1)

$$
\begin{aligned}
& (\mathrm{Bi} / \mathrm{Pb})_{\text {gas }} /(\mathrm{Bi} / \mathrm{Pb})_{\text {lava }} \\
& \quad=\left(\varepsilon_{\mathrm{Bi}} / \varepsilon_{\mathrm{Pb}}\right) /\left[\left(1-\varepsilon_{\mathrm{Bi}}\right) /\left(1-\varepsilon_{\mathrm{Pb}}\right)\right]
\end{aligned}
$$

From $\varepsilon_{\mathrm{Pb}}=0.07 \%$, we calculate a mean value for $\varepsilon_{\mathrm{Bi}}=$ $0.18( \pm 0.13) \%$, which again is low compared to that observed at Etna and Stromboli, and much lower than at Merapi (about 4\%).

\subsection{Emanation coefficient of ${ }^{210} \mathrm{Po}$}

The case of ${ }^{210} \mathrm{Po}$ is more complicated, as it has no stable isotope, and a short half-life, which allows it to decay in the gaseous phase, or to grow from ${ }^{210} \mathrm{~Pb}$ decay in the shallow degassing reservoir. The resulting ${ }^{210} \mathrm{Po}$ content measured in the aerosols is thus the budget of these two events, depending not only on $\varepsilon_{\text {Po }}$, but also on the escape time, $\theta$, for the decreasing component, and on the residence time of the degassing magma reservoir, $\tau$, for the increasing component (Gauthier et al., 2000). When both $\theta$ and $\tau$ are low compared to the ${ }^{210} \mathrm{Po}$ half-life (138 days), the ${ }^{210} \mathrm{Po} /{ }^{210} \mathrm{~Pb}$ ratio in the gas phase allows $\varepsilon_{\mathrm{Po}}$ to be estimated after Eq. (2) following:

$$
{ }^{210} \mathrm{Po} /{ }^{210} \mathrm{~Pb}=\varepsilon_{\mathrm{Po}} * A_{\mathrm{Po}} / \varepsilon_{\mathrm{Pb}} * A_{\mathrm{Pb}}
$$

which gives $\varepsilon_{\text {Po }}=2.5 \%$, assuming radioactive equilibrium in the deep magma before degassing (equal activities).

Taking into account the escape time $\theta, \varepsilon_{\text {Po }}$ has an apparent value equal to $\varepsilon_{\mathrm{Po}} * \exp -\left(\lambda_{210} \mathrm{Po} * \theta\right)$. Moreover, due to the 
Table 3. Melting and boiling temperatures of the main volatile species of $\mathrm{Pb}, \mathrm{Bi}$ and $\mathrm{Po}$ in the range of magma temperatures.

\begin{tabular}{lrrrrrrrr}
\hline & \multicolumn{2}{c}{$\mathrm{Pb}$} & & \multicolumn{2}{c}{$\mathrm{Bi}$} & & \multicolumn{2}{c}{ Po } \\
\cline { 2 - 3 } \cline { 7 - 8 } \cline { 7 - 8 } Species & $T_{m}{ }^{\circ} \mathrm{C}$ & $T_{e}{ }^{\circ} \mathrm{C}$ & & $T_{m}{ }^{\circ} \mathrm{C}$ & $T_{e}{ }^{\circ} \mathrm{C}$ & & $T_{m}{ }^{\circ} \mathrm{C}$ & $T_{e}{ }^{\circ} \mathrm{C}$ \\
\hline Metal & 327 & 1749 & & 271 & 1564 & & 254 & 962 \\
Chloride & 501 & 951 & & 230 & 447 & & 300 & 390 \\
Fluoride & 830 & 1293 & & 725 & 900 & & - & - \\
Sulfide & 1118 & - & & 850 & - & & - & - \\
\hline
\end{tabular}

viscous nature of the rhyolitic magma, it seems reasonable to conclude that the rate of convection is low. Therefore, there will be a long residence time of the shallow degassing reservoir $(\tau)$. In these conditions, the production of ${ }^{210} \mathrm{Po}$ atoms from ${ }^{210} \mathrm{~Pb}$ decay cannot be neglected, which makes the above estimated value for $\varepsilon_{\text {Po }}$ likely to be higher than in reality.

\subsection{Discussion}

Emanation coefficients $(\varepsilon)$ are closely related to the temperature of the magma and to its composition, for instance the presence or lack of $\mathrm{F}^{-}$(Gauthier et al., 2000). The emanation coefficient of $\mathrm{Pb}$ was shown to be $1 \%$ at Mount Etna (Pennisi et al., 1988), 1.5\% at Stromboli (Gauthier et al., 2000) and only $0.8 \%$ at White Island (Le Cloarec et al., 1992). $\varepsilon_{\mathrm{Bi}}$ varies from $22 \%$ in the Mount Etna plume, to $14 \%$ at Stromboli and $12 \%$ at White Island (same references, respectively). The emanation coefficient of ${ }^{210} \mathrm{Po}$ is very high at Etna and Stromboli, about $100 \%$, and $80-100 \%$ at White Island. From Table 3, it appears that $\mathrm{Pb}$ chloride, Bi fluoride and Po metal emission can be affected by the temperature of the magma, lower at Satsuma Iwojima than at Mount Etna, one of the possible causes of the very low emanation coefficients calculated for Satsuma Iwojima.

However, the lowest value for $\varepsilon_{\text {Po }}$ prior to this study was found in Merapi emissions, at about $50 \%$ (Le Cloarec and Gauthier, 2001), from which it was concluded that ${ }^{210} \mathrm{Po}$ is volatilized mostly as metal (Table 3 ). In the case of Satsuma Iwojima, the low $\varepsilon_{\text {Po }}$ is unexpected considering the magma temperature $\left(967^{\circ} \pm 17\right.$, Saito et al., 2001), higher than that of Merapi $\left(900^{\circ} \mathrm{C}\right.$, Le Guern et al., 1982). The radiogenic origin of ${ }^{210} \mathrm{Po}$ atoms, issued from ${ }^{210} \mathrm{~Pb}$ and ${ }^{210} \mathrm{Bi}$ decay, together with the high viscosity of the magma can be invoked to suggest that these isolated atoms remain trapped in the degassing magma at the place they are formed. They then decay to stable $\mathrm{Pb}$ before having time to reach the surface. Thus the emanation coefficient of ${ }^{210} \mathrm{Po}$, and probably also those of ${ }^{210} \mathrm{~Pb}$ and ${ }^{210} \mathrm{Bi}$, for the same reasons, are "apparent" emanation coefficients, and relate only to those atoms which are able to join the degassing flux.

\section{Fluxes}

An average $\mathrm{SO}_{2}$ flux of $650 \mathrm{Mg}$ /day was measured by F. Le Guern (pers. comm., 1997) at Satsuma Iwojima in November 1997. This measurement allows estimations of other elemental fluxes from the knowledge of the concentration ratio $C_{X} / C_{\mathrm{SO}_{2}}$ in the plume according to:

$$
\Phi_{X}=\Phi_{\mathrm{SO}_{2}} *\left(C_{X} / C_{\mathrm{SO}_{2}}\right) .
$$

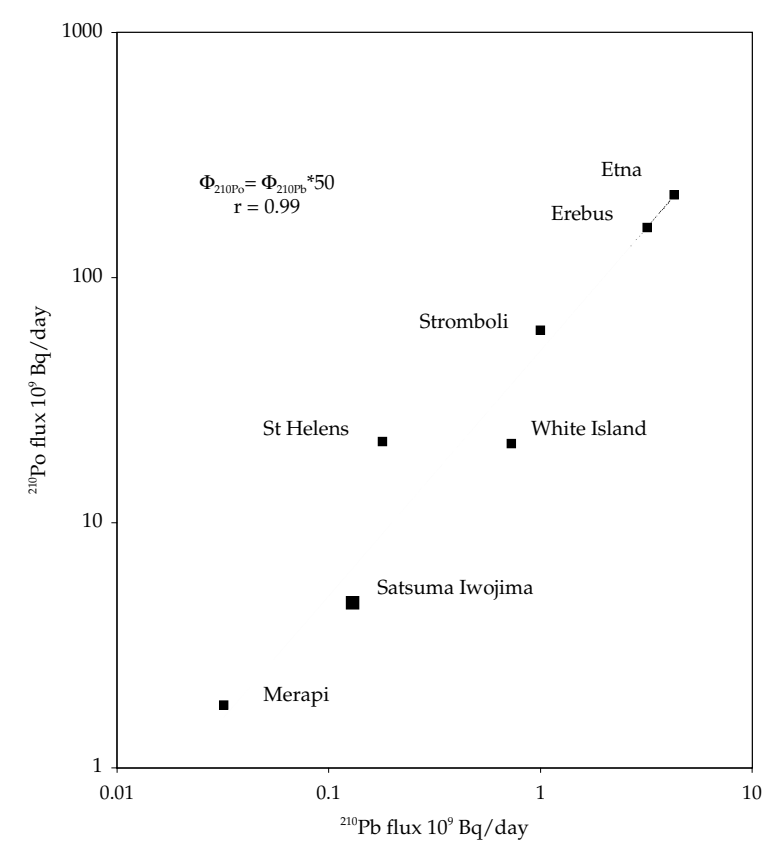

Fig. 4. Correlation between ${ }^{210} \mathrm{Po}$ flux and ${ }^{210} \mathrm{~Pb}$ flux emitted from different volcanoes.

The results for halogens, $280 \mathrm{Mg} /$ day $\mathrm{HCl}$ and $23 \mathrm{Mg}$ /day $\mathrm{HF}$, are calculated from an average $\mathrm{Cl} / \mathrm{S}=0.86$ and $\mathrm{F} / \mathrm{S}=$ 0.07. The $\mathrm{HCl}$ flux is in agreement with data reported for activity in 1990, $0.06 * 10^{6} \mathrm{Mg} /$ year (Hedenquist and Lowenstern, 1994).

For radionuclides, we obtain 4.7 and $0.13 * 10^{9} \mathrm{~Bq} /$ day of ${ }^{210} \mathrm{Po}$ and ${ }^{210} \mathrm{~Pb}$, respectively. These results indicate that very low activities are produced through the degassing of the Satsuma Iwojima magma. A comparison of present data with published results on volcanoes in different geological settings (Table 4) show a large variation in flux, in the range from 1.8 to 550 and from 0.032 to $9.6 * 10^{9} \mathrm{~Bq} / \mathrm{day}$, for ${ }^{210} \mathrm{Po}$ and ${ }^{210} \mathrm{~Pb}$, respectively. The plot $\Phi_{210} \mathrm{Po}$ versus $\Phi_{210} \mathrm{~Pb}$ shows a positive correlation (Fig. 4) between the fluxes of the two elements $(r=0.99)$ in worldwide volcanic gases, and suggests that the "law" that controls the degassing of the radionuclides does not differ significantly from one volcano to another, despite the large compositional differences between the selected volcanoes (Table 4).

According to preliminary data on radionuclide activities in lavas (Table 4), the calculated ${ }^{210} \mathrm{~Pb}$ and ${ }^{210} \mathrm{Po}$ fluxes are apparently not controlled by their activities in the magma. Rather fluxes may more reasonably be related to changes of 


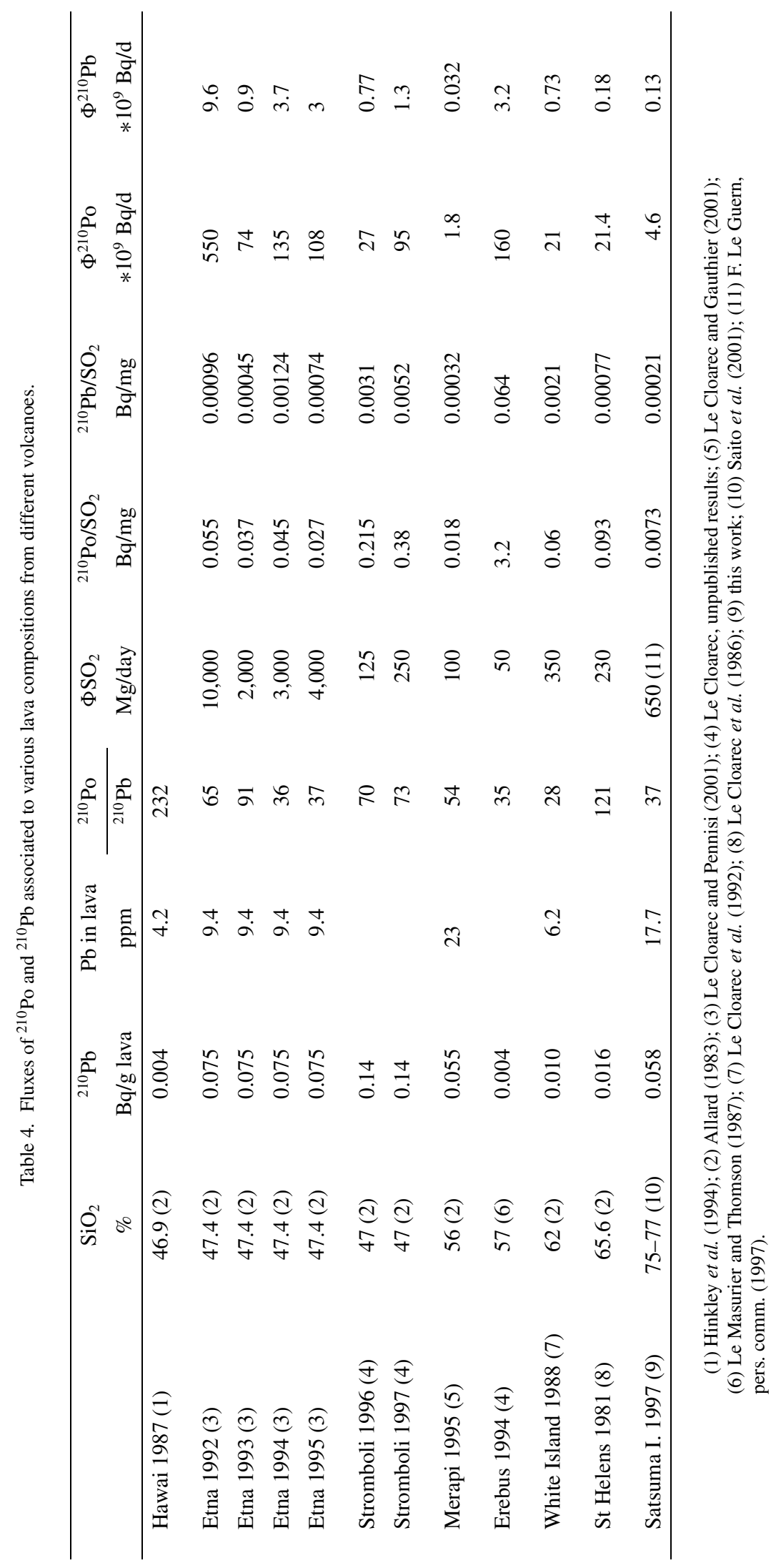


emanation coefficients controlled by the physical properties of the magma. Radionuclide fluxes determined for Satsuma Iwojima correspond to one of the lowest radionuclide fluxes yet measured, the lowest being observed at Merapi, although the corresponding $\mathrm{SO}_{2}$ flux is 2-3 times that of Stromboli, Merapi, White Island and Mount St. Helens. As observed above, the calculated emanation coefficients at Satsuma Iwojima are more than one order of magnitude lower than other silica-rich volcanoes. Comparing to basaltic volcanoes, a 40 -fold difference is observed in $\varepsilon_{\text {Po }}\left(\varepsilon_{\text {Po }}=2.5 \%\right.$ at Satsuma Iwojima and $100 \%$ at Mount Etna), whereas the difference in the emanation coefficients of $\mathrm{SO}_{2}$ is only about $15 \%\left(\varepsilon_{\mathrm{SO}_{2}}=90 \%\right.$ at Mount Etna and $82 \%$ at Satsuma Iwojima).

As a working hypothesis, we suggest that the silica content of the magma may represent a key factor in the observed range of variation of radionuclide fluxes due to the role played by increasing viscosity on elemental partition coefficients. Satsuma Iwojima represents the most silica-rich system investigated to date for the short-period and volatile radionuclides of the ${ }^{238} \mathrm{U}$ family.

Alternatively, the presence of hypersaline liquid condensed from high-pressure vapor beneath Satsuma Iwojima could be a sink for chloride-complexed metals. Hedenquist et al. (1994) suggested that this could be the reason that the flux of $\mathrm{NaCl}$ and metals measured during passive degassing of Satsuma Iwojima is about three orders of magnitude less than at White Island volcano, although the fluxes of $\mathrm{SO}_{2}$, $\mathrm{H}_{2} \mathrm{O}$ and other volatile species are similar.

\section{Volume of Degassing Reservoir}

According to the degassing model of Kazahaya et al. (2002), the shallow rhyolitic magma has a long residence time, as it was not renewed over the past 800 years. We assume that gases emitted at 3-5 km depth from the basaltic layer do not contain significant ${ }^{210} \mathrm{~Pb},{ }^{210} \mathrm{Bi}$ or ${ }^{210} \mathrm{Po}$, due to their very low vapor pressure at $90 \mathrm{MPa}$ (Pennisi and Le Cloarec, 1998). Therefore, these radionuclides are here considered to be emitted mainly from the rhyolitic magma. Thus, it is possible to estimate the volume of the rhyolitic reservoir, using the argument developed by Le Cloarec et al. (1986) to estimate the degassing volume at Mount St. Helens. Radionuclides are continuously emitted in the plume. The measured flux of ${ }^{210} \mathrm{Po}$ must then be balanced by an equal production of its radioactive precursors, ${ }^{210} \mathrm{~Pb}$ and ${ }^{210} \mathrm{Bi}$. As ${ }^{210} \mathrm{~Pb}$ has a very low emanation coefficient, most of this radionuclide remains in the rhyolite and decays to ${ }^{210} \mathrm{Bi}$, which in turn decays to ${ }^{210} \mathrm{Po}$. Bi compounds are more volatile, but the short half-life of ${ }^{210} \mathrm{Bi}$ prevents most of these atoms from reaching the atmosphere. Let $x$ be the proportion of degassed ${ }^{210} \mathrm{Bi}$ atoms and $y$ the proportion remaining in the degassing magma. The $x$ factor accounts for the emanation coefficient of ${ }^{210} \mathrm{Bi}$, and also for its decay before reaching the atmosphere, which cannot be neglected due to its short half-life. We measured ${ }^{210} \mathrm{~Pb}$ activity in Satsuma Iwojima rhyolitic lava, $0.058 \mathrm{~Bq} / \mathrm{g}$. This means that each gram of magma produces $N^{210} \mathrm{Bi}=0.058$ atom of ${ }^{210} \mathrm{Bi}$ per second $(1 \mathrm{~Bq}=1$ disintegration/sec $)$. Thus, the ${ }^{210} \mathrm{Bi}$ flux produced in the magma is $y * 0.058$ atom $/ \mathrm{sec} * \mathrm{~g}$. In a steady state, all ${ }^{210} \mathrm{Bi}$ atoms are transformed to ${ }^{210} \mathrm{Po}$ atoms, and the flux of ${ }^{210} \mathrm{Po}$ produced in the magma is also $y * 0.058$ atom $/ \mathrm{sec} * \mathrm{~g}$. We know that only $2.5 \%$ of these atoms are emitted in the gases, that is $0.025 * y * 0.058$ atom/sec $* \mathrm{~g}$. Therefore the $\left({ }^{210} \mathrm{Bi} /{ }^{210} \mathrm{Po}\right)$ activity ratio in the plume is:

$$
\begin{aligned}
& \left({ }^{210} \mathrm{Bi} /{ }^{210} \mathrm{Po}\right)=\lambda_{210} \mathrm{Bi} *(x * 0.058) / \\
& \lambda_{210} \mathrm{Po} *(y * 0.025 * 0.058) \\
& x+y=1
\end{aligned}
$$

where $\lambda$ are the radioactive constants.

From these equations, and from the $\left({ }^{210} \mathrm{Po} /{ }^{210} \mathrm{Bi}\right)$ activity ratio ( 0.6 calculated from Table 1$)$, we calculate $x=0.0005$ and $y=0.9995$, which confirms that very few ${ }^{210} \mathrm{Bi}$ atoms reach the atmosphere. The corresponding flux of ${ }^{210} \mathrm{Po}$ emitted per gram of magma is:

$\phi_{210} \mathrm{Po}=\lambda_{210} \mathrm{Po} * y * 0.025 * 0.058=7.3 * 10^{-6} \mathrm{~Bq} / \mathrm{g} *$ day.

The total ${ }^{210} \mathrm{Po}$ flux, inferred from the $\mathrm{SO}_{2}$ flux of 650 $\mathrm{Mg}$ /day (measured during the sampling; F. Le Guern, pers. comm., 1997)) and the ${ }^{210} \mathrm{Po} / \mathrm{SO}_{2}$ concentration ratio, $0.0070 \mathrm{~Bq} / \mathrm{mg}$, is $\Phi_{210} \mathrm{Po}=4.6 * 109 \mathrm{~Bq} /$ day. The $(\Phi / \phi)^{210} \mathrm{Po}$ ratio is the volume of the shallow degassing reservoir, about $0.24 \mathrm{~km}^{3}$, taking 2.7 as the magma density. This estimation is a minimum value, keeping in mind that $\varepsilon^{210} \mathrm{Po}$ is probably lower than $2.5 \%$.

Assuming that Satsuma Iwojima rhyolitic magma is undersaturated in gases (Kazahaya et al., 2002), then $\mathrm{SO}_{2}$ exsolved from the underlying basaltic layer dissolves in the upper $0.24 \mathrm{~km}^{3}$ rhyolite. Assuming a continuous $\mathrm{SO}_{2}$ degassing of $550 \mathrm{~T} /$ day over 800 years, the ratio between the amount of $\mathrm{SO}_{2}$ in the estimated rhyolite volume and the mean $\mathrm{SO}_{2}$ flux allows to roughly estimate the "residence time" of $\mathrm{SO}_{2}$ in the rhyolitic reservoir. Considering a $\mathrm{SO}_{2}$ content of $0.220 \mathrm{mg} / \mathrm{g} \mathrm{SO}_{2}$ in melt inclusions (Saito et al., 2001 ), and taking into account the $82 \%$ rate of $\mathrm{SO}_{2}$ degassing from magma to the plume (Shinohara and Saito, pers. comm., 2001), the "residence time" is calculated as 200 days. This time represents a complete turn-over of the rhyolitic magma by convection.

It is worth noting that the rhyolitic magma reservoir at Satsuma Iwojima appears to be larger than the volumes of degassing magmas from andesitic volcanoes: $0.005 \mathrm{~km}^{3}$ at White island in 1988 (Le Cloarec et al., 1992), $0.0002 \mathrm{~km}^{3}$ at Vulcano in 1988-90 (Le Cloarec et al., 1994) and 0.02 $\mathrm{km}^{3}$ at Merapi in 1995 (Le Cloarec and Gauthier, 2001).

\section{Conclusions}

Measurements of radionuclides were performed on fumarolic gases at Satsuma Iwojima, Japan, for the first time. The observed high concentrations of radionuclides in the plume, and correlations between ${ }^{210} \mathrm{Po}$ and ${ }^{210} \mathrm{~Pb}$ and between radionuclides and $\mathrm{SO}_{2}$, suggest that radionuclides and $\mathrm{SO}_{2}$ have a magmatic origin. The observed enrichment in ${ }^{210} \mathrm{Bi}$ in fumarolic samples is attributed to the decay of ${ }^{210} \mathrm{~Pb}$ sublimates deposited along the path of the gases before reaching the atmosphere.

A single set of measurements does not allow a degassing model to be developed, such as that proposed by Gauthier $e t$ 
al. (2000), even if the current activity did not change over a long period of time.

Emanation coefficients during the sampling period were estimated for $\mathrm{Pb}$ and $\mathrm{Bi}, 0.07$ and $0.18 \%$, respectively, lower than any value measured to date at other volcanoes. The maximum value of the ${ }^{210} \mathrm{Po}$ emanation coefficient is $2.5 \%$, and is likely lower, as our estimation does not take into account the long residence time of the degassing reservoir, nor the escape time of the gases. Such very low emanation coefficients are probably "apparent" emanation coefficients. Indeed, since the magma temperature at Satsuma Iwojima $\left(960-970^{\circ} \mathrm{C}\right)$ is higher than that determined at Merapi volcano, the emanation coefficients should be of the same order of magnitude at both volcanoes, based on the boiling temperatures of $\mathrm{Pb}$ and $\mathrm{Bi}$ halides and of $\mathrm{Po}$ metal. It is worthy to note that ${ }^{210} \mathrm{~Pb}$ is produced as atoms, at a concentration in the magma about $-10^{-9}$ times lower than the stable $\mathrm{Pb}$ concentration; likewise, the ${ }^{210} \mathrm{Po}$ concentration in the magma is about $10^{-15} \mathrm{~g} / \mathrm{g}$. Therefore, the high viscosity of the Satsuma Iwojima rhyolite may prevent these isolated atoms from being incorporated by the bubble flux, causing them to remain in the magma. The "apparent" emanation coefficient of radiogenic atoms corresponds to those atoms of ${ }^{210} \mathrm{~Pb}$ and ${ }^{210} \mathrm{Po}$ that reach the surface. The low value of the $\mathrm{Bi}$ emanation coefficient is related to that of ${ }^{210} \mathrm{~Pb}$, owing to the way it is calculated. Moreover, the trapping of metal chlorides by subsurface brines cannot be ruled out, which would also result in the lowering of emanation coefficients.

The implied long residence time of the rhyolitic layer allows an estimate of its volume, about $0.24 \mathrm{~km}^{3}$, which is the volume of magma that will produce the observed continuous flux of ${ }^{210} \mathrm{Po}$. The turn-over time of the rhyolitic magma inferred from its volume is estimated to be about 200 days.

Our conclusions are consistent with the degassing model proposed by Kazahaya et al. (2002), provided the viscosity of the rhyolitic layer is high enough to trap isolated radionuclide atoms, but is not so high that convection of the rhyolitic magma is impeded.

Acknowledgments. The authors are grateful to all those who contributed to the sampling, particularly Dr. F. Le Guern and Dr. H. Shinohara. We appreciate the useful comments of Dr. H. Shinohara, Dr. Y. Taran, Dr. U. Fehn and Dr. J. Hedenquist who helped to greatly improve the manuscript. We thank Dr. H. Shinohara and Dr. G. Saito for communicating unpublished S contents in melt inclusions and matrix glass. Contribution LSCE 0730.

\section{References}

Allard, P., The origin of hydrogen, carbon, sulphur, nitrogen and rare gases in volcanic exhalations: evidence from isotope chemistry, in Forecasting Volcanic Events, edited by H. Tazieff and J. C. Sabroux, pp. 337-386, Elsevier, Amsterdam, 1983.

Faivre-Pierret, $\mathrm{R}$., $\mathrm{SO}_{2}, \mathrm{HCl}$ and $\mathrm{HF}$ detection and dosing in the volcanic gas phase, in Forecasting Volcanic Events, edited by H. Tazieff and J. C.
Sabroux, pp. 399-408, Elsevier, Amsterdam, 1983.

Gauthier, P. J., M. F. Le Cloarec, and M. Condomines, Degassing processes at Stromboli volcano inferred from short-lived disequilibria $\left({ }^{210} \mathrm{~Pb}\right.$ ${ }^{210} \mathrm{Bi}^{2}{ }^{210} \mathrm{Po}$ ) in volcanic gases, J. Volcanol. Geotherm. Res., 102, 1-19, 2000

Gill, J. B., R. Williams, and K. Bruland, Eruption of basalt and andesite lava degasses ${ }^{222} \mathrm{Rn}$ and ${ }^{210} \mathrm{Po}$, Geophys. Res. Lett., 12(1), 17-20, 1985.

Hedenquist, J. W. and J. B. Lowenstern, The role of magmas in the formation of hydrothermal ore deposits, Nature, 370, 519-527, 1994.

Hedenquist, J. W., A. Masahiro, and H. Shinohara, Flux of volatiles and ore-forming metals from the magmatic-hydrothermal system of Satsuma Iwojima volcano, Geology, 22, 585-588, 1994.

Hinkley, T. K., M. F. Le Cloarec, and G. Lambert, Fractionation of families of major, minor, and trace metals across the melt-vapour interface in volcanic exhalations, Geochim. Cosmochim. Acta, 58, 3255-3263, 1994.

Kazahaya, K., H. Shinohara, and G. Saito, Degassing process of SatsumaIwojima volcano, Japan: Supply of volatile components from a deep magma chamber, Earth Planets Space, 54, this issue, 327-335, 2002.

Lambert, G., M.-F. Le Cloarec, B. Ardouin, and J.-C. Le Roulley, Volcanic emission of radionuclides and magma dynamics, Earth Planet. Sci. Lett., 76, 185-192, 1986.

Le Cloarec, M. F. and P. J. Gauthier, Merapi Volcano: a study case of radionuclide behaviour in hot volcanic gases, J. Geophys. Res., 2001 (submitted).

Le Cloarec, M. F., G. Lambert, J. C. Le Roulley, and B. Ardouin, Longlived radon decay products in Mount Saint Helens emissions: an estimation of the magma reservoir volume, J. Volcanol. Geotherm. Res., 28, 85-89, 1986.

Le Cloarec, M. F., P. Allard, B. Ardouin, W. Giggenbach, and D. S. Sheppard, Radioactive isotopes and trace elements in gaseous emissions from White Island, New Zealand, Earth Planet. Sci. Lett., 108, 19-28, 1992.

Le Cloarec, M. F., M. Pennisi, E. Corazza, and G. Lambert, Origin of fumarolic fluids emitted from a nonerupting volcano: Radionuclide constraints at Vulcano (Aeolian Islands, Italy), Geochim. Cosmochim. Acta, 58, 4401-4410, 1994.

Le Cloarec, M. F. and M. Pennisi, Radionuclide and sulfur content in Mount Etna plume: new constraints on the magma feeding system, J. Volcanol. Geotherm. Res., 108, 141-155, 2001.

Le Guern, F., J. C. Le Roulley, and G. Lambert, Condensation du polonium dans les gaz volcaniques, C.R. Acad. Sci., 294, 887-890, 1982.

Le Masurier, W. E. and J. W. Thomson, (Editors), Volcanoes of the Antarctic plate and Southern Oceans, Antarctic Res. Ser., 48, 103-108, 1987.

Pennisi, M. and M. F. Le Cloarec, Variations of $\mathrm{Cl}$, F, and S in Mount Etna's plume, Italy, between 1992 and 1995, J. Geophys. Res., 103(B-3), 5061-5066, 1998.

Pennisi, M., M.-F. Le Cloarec, G. Lambert, and J. C. Le Roulley, Fractionation of metals in volcanic emissions, Earth Planet. Sci. Lett., 88, 284-288, 1988.

Polian, G. and G. Lambert, Radon daughters and sulfur output from Erebus volcano, Antarctica, J. Volcanol. Geotherm. Res., 6, 125-137, 1979.

Saito, G., K. Kazahaya, Y. Kawanabe, and J. A. Stimac, Volatile evolution of high temperature rhyolite in the post-caldera magma chamber of Satsuma Iwojima volcano, Japan, IAVCEI General Assembly abstract, 50, 1997.

Saito, G., K. Kazahaya, H. Shinohara, J. Stimac, and Y. Kawanabe, Variation of volatile concentration in a magma system of Satsuma-Iwojima volcano deduced from melt inclusions analyses, J. Volcanol. Geotherm. Res., 108, 11-31, 2001.

Shinohara, H., W. F. Giggenbach, K. Kazahaya, and J. W. Hedenquist, Geochemistry of volcanic gases and hot springs of Satsuma Iwojima, Japan: Following Matsuo, Geochem. J., 27, 271-285, 1993.

M. F. Le Cloarec (e-mail: Marie-Francoise.Le-Cloarec@1sce.cnrs-gif.fr) and M. Pennisi 